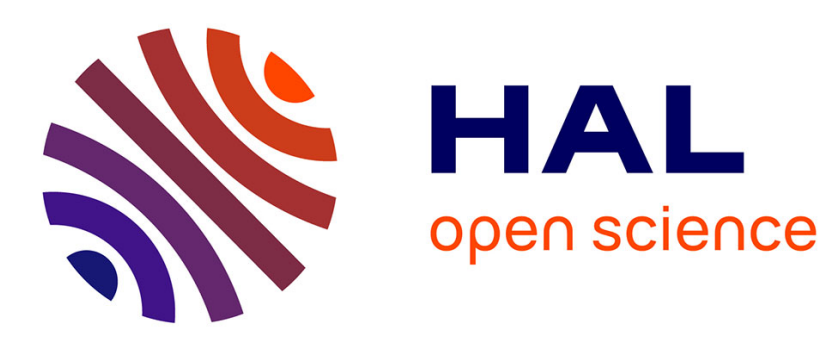

\title{
VUV-induced dissociation of methylchlorosilanes, studied by electronion coincidence spectroscopy
}

\author{
E Kukk, K Kooser, Dt Ha, S Granroth, E Nõmmiste
}

\section{To cite this version:}

E Kukk, K Kooser, Dt Ha, S Granroth, E Nõmmiste. VUV-induced dissociation of methylchlorosilanes, studied by electronion coincidence spectroscopy. Journal of Physics B: Atomic, Molecular and Optical Physics, 2010, 43 (6), pp.65103. 10.1088/0953-4075/43/6/065103 . hal-00569881

\section{HAL Id: hal-00569881 \\ https://hal.science/hal-00569881}

Submitted on 25 Feb 2011

HAL is a multi-disciplinary open access archive for the deposit and dissemination of scientific research documents, whether they are published or not. The documents may come from teaching and research institutions in France or abroad, or from public or private research centers.
L'archive ouverte pluridisciplinaire HAL, est destinée au dépôt et à la diffusion de documents scientifiques de niveau recherche, publiés ou non, émanant des établissements d'enseignement et de recherche français ou étrangers, des laboratoires publics ou privés. 


\title{
VUV-induced dissociation of methylchlorosilanes, studied by electron-ion coincidence spectroscopy
}

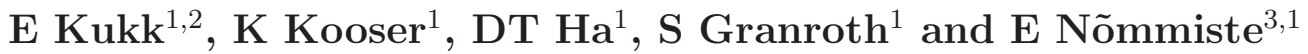 \\ ${ }^{1}$ Department of Physics and Astronomy, University of Turku, Vesilinnantie 5, \\ FI-20014 Turku, Finland \\ ${ }^{2}$ Turku University Centre for Materials and Surfaces (MatSurf), Turku, Finland \\ ${ }^{3}$ Institute of Physics, University of Tartu, Riia 142, 51014 Tartu, Estonia \\ E-mail: edwin.kukk@utu.fi
}

\begin{abstract}
Fragmentation patterns of gas-phase trimethylchlorosilane and methyltrichlorosilane molecules were investigated using the electron-energy-resolved photoelectron-photoion coincidence (PEPICO) technique. Production of parent ions and the dominant fragments by $30 \mathrm{eV}$ synchrotron radiation was followed as a function of the photoelectron binding energy. Ion appearance energies were determined from these coincident ion yield curves. The fragmentation patterns and their development is discussed in terms of available internal excess energy as well as the molecular orbital character of the parent molecules. A common dissociation scenario is proposed for both molecules, producing methyl- and chlorine-loss fragments at lower excess energies and smaller fragments through second-step processes at sufficiently high energies.
\end{abstract}

PACS numbers: $33.80,33.20,33.15,31.15$

Submitted to: J. Phys. B: At. Mol. Phys.

\section{Introduction}

Silane chemistry is central in many industrial applications where the properties of materials need to be modified and improved. Organofunctional silanes are used as adhesion promoters, as hydrophobic coatings, as drying agents, for cross-linking polymer chains and as polymer end-caps. In the often demanding applications these molecules can be subjected to the ionizing ultraviolet radiation which damages the molecular structure and eventually leads to the degradation of the material's properties.

Two silane derivatives, trimethylchlorosilane $\mathrm{Me}{ }_{3} \mathrm{ClSi}$ and methyltrichlorosilane $\mathrm{MeCl}_{3} \mathrm{Si}$ were chosen for this study ( $\mathrm{Me}$ denotes the methyl group $\mathrm{CH}_{3}$ ). These molecules are highly symmetric and have a relatively simple electronic structure so that useful information about it can still be extracted by ultraviolet photoelectron spectroscopy (UPS). The purpose of this experiment was to investigate in detail the fragmentation mechanisms of these molecules using energy-resolved electron-ion 
coincidence technique (PEPICO) [1, 2]. Hartree-Fock molecular orbital calculations are used as an aid to interpret and assign the photoemission features.

Molecular fragmentation is commonly studied by partial ion yield (PIY) measurements, following ion production as a function of the ionizing photon energy $[3,4,5,6,7]$. The PIY curves (also referred to as the photoionization efficiency curves (e.g. Ref. [8]) over the UV- and VUV photon energy range are very useful for accurate determination of adiabatic ionization energies and ion appearance energies. From the applied point of view, the branching ratios of various fragments at different radiation energies, provided by PIY and ion time-of-flight (TOF) spectra, are also valuable. However, from the fundamental viewpoint, it is more relevant to study the fragmentation process as a function of the total available excess internal energy of the parent molecular cation, defined as the difference of the electronic and vibrational energy immediately after photoionization from the adiabatic ground-state energy of the cation. Since the photoelectrons from various electronic and vibrational levels carry away an undetermined amount of energy, such information is not available in PIY spectra, whereas in electron-energy-resolved PEPICO $[9,10,11]$ or in threshold PEPICO $[12,13]$ spectroscopy the internal excess energy is a well determined parameter. Energy-resolved PEPICO technique also allows to directly correlate the production of various charged fragments with the ionization of specific molecular orbitals.

The valence electronic structure of all methylchlorosilanes $\mathrm{Me}_{n} C l_{4-n} S i \quad(n=1-3)$ molecules has been investigated by photoelectron spectroscopy using He I radiation [14] and a lower quality spectrum of $\mathrm{Me}_{3} \mathrm{ClSi}$ has been published [15]. Also relevant is an early extensive study of many halosilanes by Frost et al. [16]. There have been a number of studies for the determination of ionization potentials and ion appearance energies of selected methylchlorosilanes $[17,18,19,20]$. More recently, Lu et al. performed a mass spectroscopy and PIY study of various fragments of methyltrichlorosilane [21] and dimethyldichlorosilane [22] in the VUV photon energy range, complemented with $a b$ initio calculations of molecular structure. Dissociation of the methylsilane molecule in the vicinity of Si $1 s$ edge has been investigated using PEPICO techniques [23], but to our knowledge the only closely related PEPICO study in the VUV photon energy range was performed by Szepes and Baer on the dissociation of hexamethyldisilane molecules, using threshold PEPICO as a means to determine the internal energy [24].

\section{Experimental}

The experiment was performed at the FinEst branchline at NIM-beamline I3 of MAXIII synchrotron radiation facility (Lund, Sweden) [25]. The samples of trimethylchloroand methyltrichlorosilane were purchased from Sigma-Aldrich. The measurements were carried out using the joint PEPICO setup of Oulu and Turku Universities, described in detail in Ref. [26]. Briefly, the setup consists of a modified Scienta SES-100 electron energy analyzer [27], where the original CCD camera was replaced by a resistive anode detector (Quantar), and a home-made Wiley-Mclaren type ion time-of-flight detector 
with a $400 \mathrm{~mm}$ long drift tube. The ion spectrometer is equipped by $77 \mathrm{~mm}$ Hamamatsu MCP detector. The ion detection electronics is based on a $1 \mathrm{GHz}$ waveform digitizer card (Signatec PDA 1000). For the PEPICO measurements, the PEPICO system is operated in the pulsed extraction field mode and in the present experiment the extraction pulse voltage was $300 \mathrm{~V}$ across the sample region, with the drift tube held at $-800 \mathrm{~V}$. The ion extraction pulses were triggered by the fast preamplifier signal from the electron detector. The ions were measured in coincidence with the valence and inner-valence photoelectrons using the photon energy of $30 \mathrm{eV}$ at $2 \mathrm{meV}$ resolution. The electron analyzer was operated at the pass energy of $100 \mathrm{eV}$ and with the instrumental resolution of $220 \mathrm{meV}$ FWHM as determined from Ar $3 p$ photoelectron lines. The electron binding energy scale was calibrated using the vertical ionization energy of $12.622 \mathrm{eV}$ of water molecules [28] and the $\mathrm{H}_{2} \mathrm{O}^{+}$coincident ion yield curve.

The PEPICO data always contain some false coincidences of particles not originating from the same molecule. The probability of such events was kept small by using low counting rates of about 10 electrons/s. In addition, artificial coincidence events were created during the measurement by a pulse generator so that two ion-ion coincidence maps were collected simultaneously one in coincidence with electrons and one triggered by pulse generator. The false coincidence background has been subtracted from the ion yield curves presented below.

\section{Results and discussion}

\subsection{Electronic structure}

The photoelectron spectra of $\mathrm{Me}_{3} \mathrm{ClSi}$ and $\mathrm{MeCl}_{3} \mathrm{Si}$ were recorded both in a separate electron spectroscopy measurement and as a part of the PEPICO measurement. However, these electron spectra contain some contamination structure from residual gases and possibly from the impurities in the sample. Instead of noncoincident electron spectra, Fig. 1 presents the coincidence ion yields (CIYs) as a function of the coincident electron's binding energy (note that in contrast PIY refers to noncoincident ion yields measured as a function of photon energy). The curves were obtained as sums of the yields of the parent molecular ions and all the fragments that can be associated with the molecules. The exception was the fragment with $\mathrm{m}=28 \mathrm{a}$.m.u. that can be either atomic silicon or $N_{2}^{+}$from the residual gas, but a closer investigation showed that the structure lacks the isotopic constitution of $\mathrm{Si}$ and was assigned as $N_{2}^{+}$. The false coincidence events were subtracted from the ion yield curves. Such sums can be considered to represent the "purified" electronic structure of the molecule.

The structures in Fig. 1 have been assigned with the help of ab initio molecular orbital calculations that were executed with the GAMESS (The General Atomic and Molecular Electronic Structure System) program [29]. The molecular orbital calculations and geometry optimization for the neutral ground state of the parent molecules were carried out by the restricted Hartree-Fock (RHF) method [30] with the split-valence 


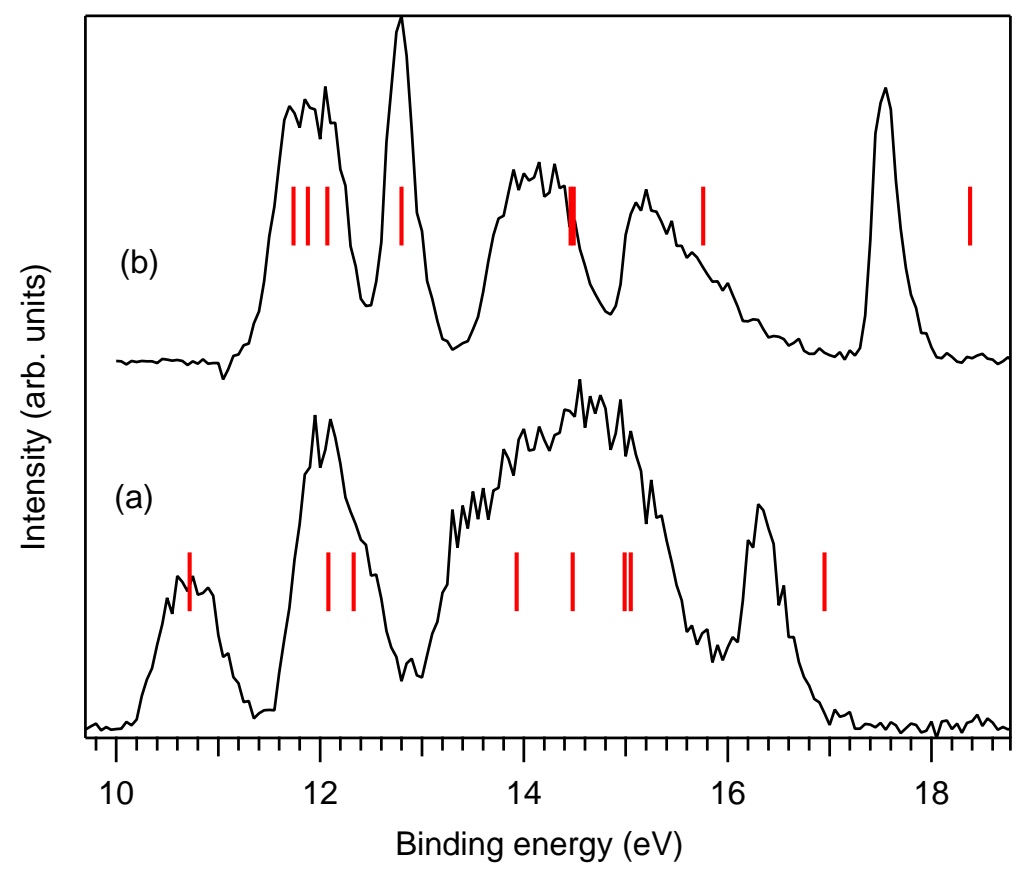

Figure 1. Total yield curves of the parent and fragment ions of trimethylchlorosilane (a) and methyltrichlorosilane (b). Vertical bars refer to the molecular orbital assignment given in Table 1.

6-31(dp) basis set [31] containing d- and p-polarization functions.

Taking the electron binding energies equal to the negative of the orbital energies according to the Koopmans' theorem appears sufficient for the assignment of the spectral features in Fig. 1, as given in Table 1. As expected, Koopmans' theorem overestimates the binding energies, since electronic relaxation is negleced. For the ease of comparison with the experiment the calculated values are shifted by empirical constants, $-0.7 \mathrm{eV}$ for trimethylchlorosilane and $-0.8 \mathrm{eV}$ for methyltrichlorosilane, so that the HOMO energies are aligned with the spectral peak. Only the outermost MOs that fit into the binding energy range of Fig. 1 are listed in Table 1. Table 1 also gives the qualitative description of the dominant character of each MO. As seen from Fig. 1, the calculation has more strongly overestimated the binding energies of the inner valence orbitals, which is expected since inner valence holes induce larger orbital relaxation to the HOMO orbital than the HOMO vacancy does to the inner valence orbitals.

The HOMO of $\mathrm{Me}_{3} \mathrm{ClSi}$ consists, according to the calculation, of doubly degenerate orbitals of $E$-symmetry in the $C_{3 v}$ point group of the molecule. These orbitals have mostly the silicon-methyl $\sigma$ - bonding properties, but populate also the chlorine lonepair $3 p$ orbitals. A single-peak structure around $10.7 \mathrm{eV}$ in spectrum (a) corresponds to these orbitals. In $\mathrm{MeCl}_{3} \mathrm{Si} \mathrm{HOMO}$ has the $\mathrm{A}_{2}$ symmetry and is mostly of chlorine $3 p$ character. However, the next MOs lie close in energy and thus their ordering can be uncertain. More elaborate calculations of the cationic electronic states with full electronic and nuclear relaxation have found the lowest-energy state to be ${ }^{2} A_{1}$ and the 
next ${ }^{2} A_{2}$ [21], although this gives the ordering of adiabatic, not vertical transitions. Ionization of the first four MOs form a single structure in spectrum (b) that is shifted to higher binding energies by about $1 \mathrm{eV}$ compared to the spectrum (a) reflecting the higher ionization energy of a more chlorinated species.

The next feature is assigned to three MOs $\left(13,14 e\right.$ and $\left.12 a_{1}\right)$ in spectrum (a) of $\mathrm{Me}_{3} \mathrm{ClSi}$, but to two degenerate orbitals $(19,20 \mathrm{e})$ in spectrum (b) of $\mathrm{MeCl}_{3} \mathrm{Si}$. This peak at $E_{b}=12.8 \mathrm{eV}$ in spectrum (b) is also very sharp, with the FWHM of about $250 \mathrm{meV}$. After the instrumental broadening (Gaussian with $220 \mathrm{meV}$ FWHM) is taken into account, the actual width of the feature is only about $130 \mathrm{meV}$. The corresponding MOs of this peak have the chlorine lone pair character, the ionization from which is indeed typically associated with bound ionic states and sharp features in photoelectron spectra.

The next features are considerably broader, with two separate structures in case of methyltrichlorosilane and one very broad structure in trimethylchlorosilane. The corresponding MOs are mainly responsible for the bonding within the individual methyl groups in $\mathrm{Me}_{3} \mathrm{ClSi}$, but are of more mixed bonding character in $\mathrm{MeCl}_{3} \mathrm{Si}$. The strong bonding properties of the orbitals together with the breadth of the spectral features suggests that these final ionic states are created in a repulsive region of their potential energy surfaces and either start to dissociate immediately or become highly vibrationally excited. The highest binding energy peaks in the spectra again correspond to a single, totally symmetric $\mathrm{MO}\left(10 a_{1}\right.$ in $\mathrm{Me}_{3} \mathrm{ClSi}$ and $11 a_{1}$ in $\mathrm{MeCl}_{3} \mathrm{Si}$ ), and are relatively sharp, although these orbitals also contribute to the molecular bonding.

\subsection{Molecular fragmentation}

The photoelectron-photoion coincidence map of $\mathrm{MeCl}_{3} S i$ is shown in Fig. 2 where the main observed ions and their appearance energies from literature [21] have been marked. The map is a grayscale two-dimensional histogram of true electron-ion coincidences, from which the false coincidence map has been subtracted. It is given as an illustration of the measurement; the actual analysis is performed on the CIY curves, extracted from this dataset for $\mathrm{MeCl}_{3} \mathrm{Si}$ and from a similar one for $\mathrm{Me}_{3} \mathrm{ClSi}$. The CIY curves are seen in the map as horizontal bands. The fine structure of the bands arises from the isotopic composition of the silicon and chlorine atoms. For example, the strongest band assigned to the $\mathrm{SiCl}_{3}^{+}$ion is composed of four main lines arising from various ${ }^{35} \mathrm{Cl}$ and ${ }^{37} \mathrm{Cl}$ combinations. Whenever the assignment of a structure was in doubt, its isotopic fine structure was used as an aid. All analysis of the CIY curves was performed after the subtraction of false coincidence events. This procedure was done as described in Section 2 and is demostrated by Fig. 3 in the case of $\mathrm{MeCl}_{3} \mathrm{Si}^{+}$and $\mathrm{ClSi}^{+}$ions from the $\mathrm{MeCl}_{3} \mathrm{Si}$ molecule.

Figure 4 displays the coincident ion yields of the parent and major fragment ions for trimethylchlorosilane (a) and methyltrichlorosilane (b). The observed ions and their absolute appearance energies as well as the excess energies above the ionization potential 
Table 1. Molecular oribital properites of methylchlorosilanes. $\epsilon$ is the ab initio orbital energy and $E_{b}$ is the electron binding energy with an empirical correction. Under Character, "Me" indicates bonding within the methyl groups

\begin{tabular}{|c|c|c|c|c|}
\hline Orbital & $\epsilon(\mathrm{eV})$ & $E_{b}(\mathrm{eV})$ & Character & Main ionic fragments \\
\hline \multicolumn{5}{|c|}{ Trimethylchlorosilane } \\
\hline $15 e, 16 e$ & -11.42 & 10.72 & $\mathrm{Si}-\mathrm{Me}, \mathrm{Cl} 3 p$ & $\mathrm{Me}_{3} \mathrm{ClSi}, \mathrm{Me}_{2} \mathrm{ClSi}$ \\
\hline $13 e, 14 e$ & -12.78 & 12.08 & $\mathrm{Si}-\mathrm{Cl}, \mathrm{Si}-\mathrm{Me}$ & $\mathrm{Me}_{2} \mathrm{ClSi}, \mathrm{Me}_{3} \mathrm{Si}$ \\
\hline $12 a_{1}$ & -13.03 & 12.33 & $\mathrm{Si}-\mathrm{Cl}, \mathrm{Si}-\mathrm{Me}$ & $\mathrm{Me}_{2} \mathrm{ClSi}, \mathrm{Me}_{3} \mathrm{Si}$ \\
\hline $1 a_{2}$ & -14.63 & 13.93 & $\mathrm{Me}$ & $\mathrm{Me}_{2} \mathrm{ClSi}, \mathrm{Me}_{3} \mathrm{Si}$ \\
\hline $11 e, 12 e$ & -15.18 & 14.48 & $\mathrm{Me}$ & $\mathrm{Me}_{2} \mathrm{ClSi}, \mathrm{Me}_{3} \mathrm{Si}$ \\
\hline $9 e, 10 e$ & -15.69 & 14.99 & $\mathrm{Me}$ & $\mathrm{Me}_{2} \mathrm{ClSi}, \mathrm{Me}_{3} \mathrm{Si}, \mathrm{H}_{2} \mathrm{ClSi}$ \\
\hline $11 a_{1}$ & -15.75 & 15.05 & $\mathrm{Me}$ & $\mathrm{Me}_{2} \mathrm{ClSi}, \mathrm{Me}_{3} \mathrm{Si}, \mathrm{H}_{2} \mathrm{ClSi}$ \\
\hline $10 a_{1}$ & -17.65 & 16.95 & $\mathrm{Si}-\mathrm{Me}, \mathrm{Si}-\mathrm{Cl}$ & $\mathrm{H}_{2} \mathrm{ClSi} \mathrm{H}_{4} \mathrm{CSi}$ \\
\hline \multicolumn{5}{|c|}{ Methyltrichlorosilane } \\
\hline $2 a_{2}$ & -12.54 & 11.74 & $\mathrm{Cl} 3 p$ & $\mathrm{MeCl}_{3} \mathrm{Si}$ \\
\hline $13 a_{1}$ & -12.68 & 11.88 & Si-Me, Cl $3 p$ & $\mathrm{MeCl}_{3} \mathrm{Si}_{\mathrm{Cl}} \mathrm{Cl}_{3} \mathrm{Si}$ \\
\hline $21 e, 22 e$ & -12.87 & 12.07 & $\mathrm{Cl} 3 p$ & $\mathrm{Cl}_{3} \mathrm{Si}$ \\
\hline $19 e, 20 e$ & -13.60 & 12.80 & $\mathrm{Cl} 3 p$ & $\mathrm{Cl}_{3} \mathrm{Si}, \mathrm{MeCl}_{2} \mathrm{Si}$ \\
\hline $12 a_{1}$ & -15.26 & 14.46 & $\mathrm{Si}-\mathrm{Me}, \mathrm{Cl}-\mathrm{Cl}, \mathrm{Me}$ & $\mathrm{Cl}_{3} \mathrm{Si}, \mathrm{MeCl}_{2} \mathrm{Si}$ \\
\hline $17 e, 18 e$ & -15.29 & 14.49 & $\mathrm{Si}-\mathrm{Cl}, \mathrm{Me}$ & $\mathrm{Cl}_{3} \mathrm{Si}, \mathrm{MeCl}_{2} \mathrm{Si}$ \\
\hline $15 e, 16 e$ & -16.56 & 15.76 & $\mathrm{Me}$ & $\mathrm{Cl}_{3} \mathrm{Si}, \mathrm{MeCl}_{2} \mathrm{Si}$ \\
\hline $11 a_{1}$ & -19.18 & 18.38 & $\mathrm{Si}-\mathrm{Cl}, \mathrm{Si}-\mathrm{Me}$ & $\mathrm{ClSi}, \mathrm{H}_{2} \mathrm{CCl}$ \\
\hline
\end{tabular}

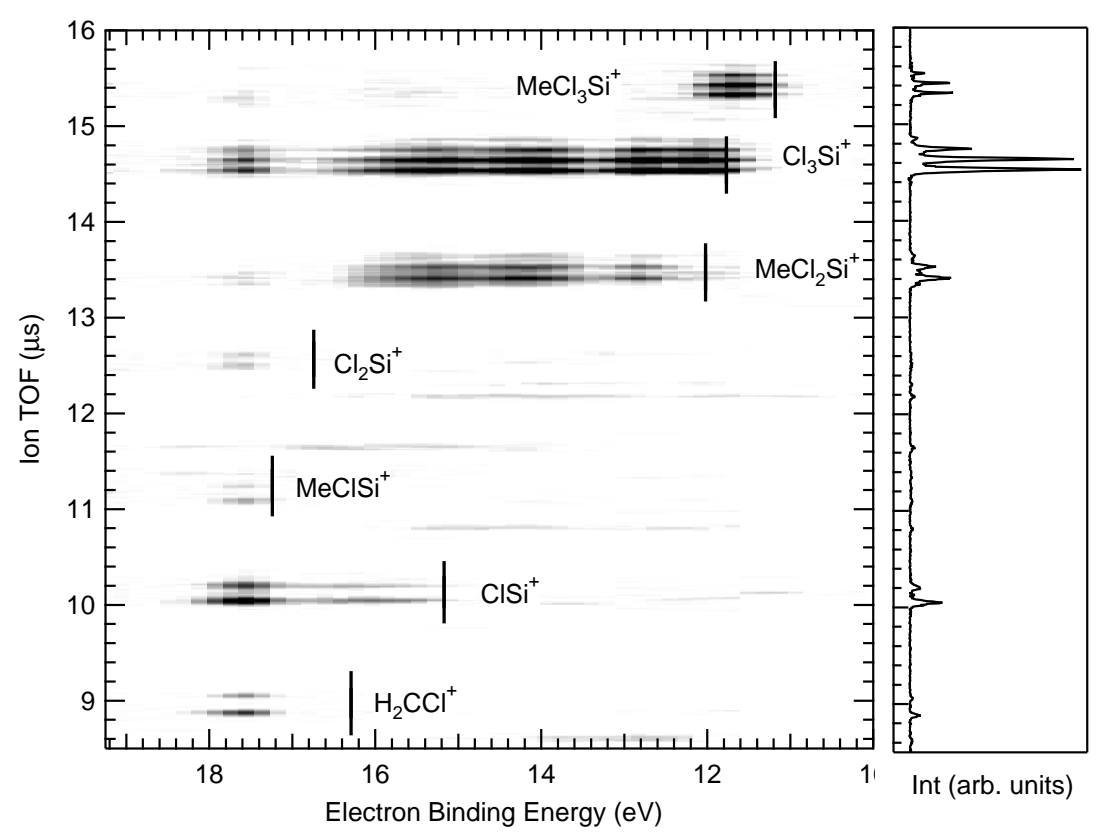

Figure 2. Electron-energy-resolved Photoelectron-Photoion Coincidence (PEPICO) map of methyltrichlorosilane. Vertical bars mark the appearance energies of fragment ions from Ref. [21]. Ion TOF spectrum of all coincidence events is shown in the right-hand panel. 


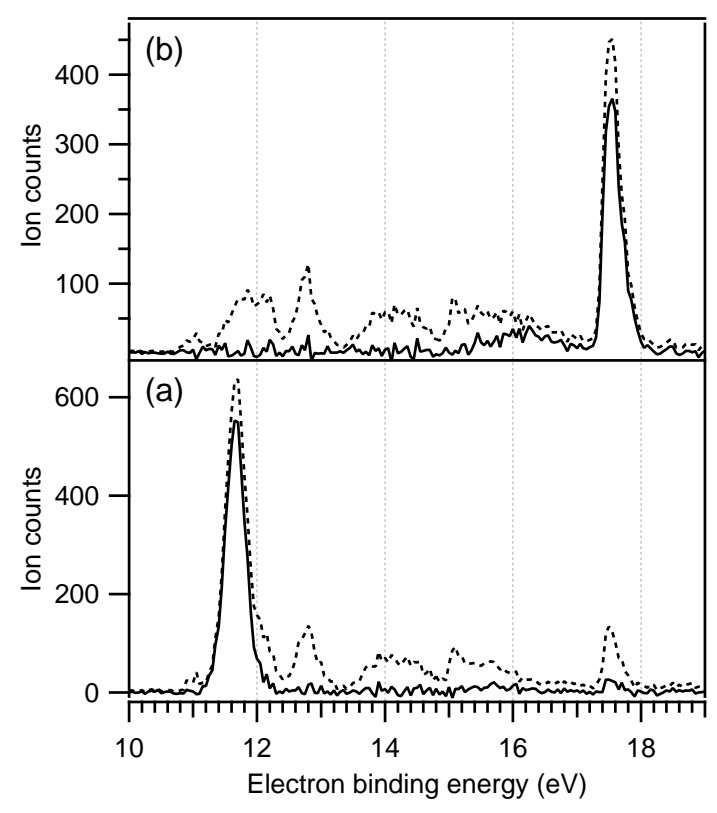

Figure 3. Coincident ion yields of (a) $\mathrm{MeCl}_{3} \mathrm{Si}^{+}$and (b) $\mathrm{ClSi}^{+}$ions from the $\mathrm{MeCl}_{3} \mathrm{Si}$ molecule before (dotted lines) and after (solid lines) the false event background subtraction.

Table 2. Parent ions and main observed fragments of methylchlorosilanes, their appearance $\left(E_{a}\right)$ and excess $\left(E_{e}\right)$ energies. Literature values for the first ionization energy and available ion appearance energies are given in the last column.

\begin{tabular}{lccl}
\hline Fragment & $E_{a}(\mathrm{eV})$ & $E_{e}(\mathrm{eV})$ & \multicolumn{2}{l}{$E_{a}^{\text {lit }}(\mathrm{eV})$} \\
\hline \multicolumn{4}{l}{ Trimethylchlorosilane } \\
$\mathrm{Me}_{3} \mathrm{ClSi} i^{+}$ & $10.24(10)$ & 0.00 & $10.65(2)[24]$ \\
$\mathrm{Me}_{2} \mathrm{ClSi}^{+}$ & $10.49(10)$ & 0.25 & $10.6(1)[20]$ \\
$\mathrm{Me}_{3} \mathrm{Si}^{+}$ & $11.51(10)$ & 1.27 & $10.9(1)[19]$ \\
$\mathrm{H}_{2} \mathrm{ClSi}^{+}$ & $14.4(3)$ & 4.2 & \\
$\mathrm{H}_{4} \mathrm{CSi}^{+}$ & $14.9(3)$ & 4.6 & \\
\hline $\mathrm{Methyltrichlorosilane}$ & & \\
$\mathrm{MeCl}_{3} \mathrm{Si}^{+}$ & $11.39(10)$ & 0.00 & $11.36(3)[17], 11.18[21]$ \\
$\mathrm{Cl}_{3} \mathrm{Si}^{+}$ & $11.64(10)$ & 0.26 & $11.77[21]$ \\
$\mathrm{MeCl}_{2} \mathrm{Si}^{+}$ & $12.40(10)$ & 1.01 & $12.02[21]$ \\
$\mathrm{ClSi}^{+}$ & $15.2(3)$ & 3.8 & $15.17[21]$ \\
$\mathrm{H}_{2} \mathrm{CCl}^{+}$ & $17.4(2)$ & 6.0 & $16.29[21]$ \\
\hline
\end{tabular}

are listed in Table 2.

The parent ion CIY's of both molecules are well represented by nearly Gaussian peak shapes. In $\mathrm{MeCl}_{3} \mathrm{Si}$ it has the maximum at $11.65 \mathrm{eV}$ electron binding energy and the FWHM of $364 \mathrm{meV}$, by least-squares curve fitting [32]. For $\mathrm{Me}_{3} \mathrm{ClSi}$ the peak maximum is at $10.50 \mathrm{eV}$ and the FWHM is $362 \mathrm{meV}$. In order to compare this result with the parent ion appearance energies (corresponding to the adiabatic ionization 

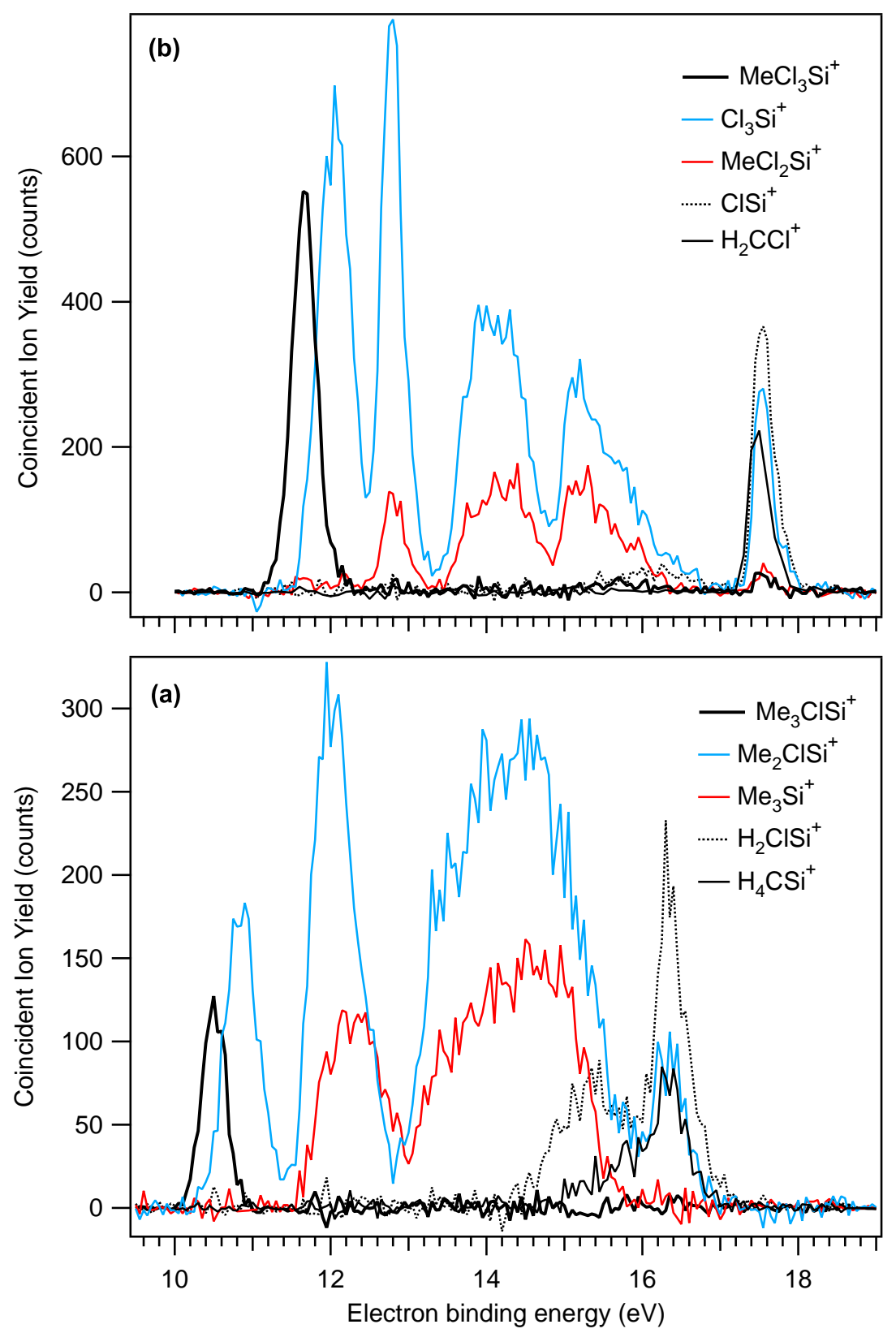

Figure 4. Coincident ion yield (CIY) curves of the main dissociation fragments of trimethylchlorosilane (a) and methyltrichlorosilane (b).

potentials), the fitted Gaussian shape was deconvoluted by the Gaussian instrument function of $220 \mathrm{meV}$ FWHM, obtaining the FWHM of the parent ion yield as about $290 \mathrm{meV}$ for both molecules. In order to have a systematic procedure for appearance energy $\left(E_{a}\right)$ determination from the CIY curves that also takes into account the large instrumental broadening, we calculated the zero-crossing energy of the slope line, drawn from the deconvoluted Gaussian curve at the point $\left(E_{0}-\Gamma\right)$ :

$$
G(E)=\exp \frac{-\left(E-E_{0}\right)^{2}}{\Gamma^{2}}
$$




$$
\begin{aligned}
& \left.G^{\prime}(E)\right|_{\left(E=E_{0}-\Gamma\right)}=\frac{2}{e} \frac{1}{\Gamma} \\
& E_{a}=E_{0}-\Gamma-\frac{1}{\left.e G^{\prime}(E)\right|_{\left(E=E_{0}-\Gamma\right)}}=E_{0}-\frac{3}{2} \Gamma .
\end{aligned}
$$

The appearance energies thus obtained are listed in Table 2. In some cases, significant discrepancies can be seen with published values obtained by other methods, which can be due to different interpolation procedures and the fact that the behaviour of the PIY and CIY curves above the appearance threshold is qualitatively different. Particularly in the case of the $\mathrm{H}_{2} \mathrm{CCl}^{+}$ion the appearance energy reported by $\mathrm{Lu}$ et al. is by $1.1 \mathrm{eV}$ lower than from the present experiment. Notably, their value of $16.29 \mathrm{eV}$ falls in the gap in the binding energy scale of available electronic states of $\mathrm{MeCl}_{3} \mathrm{Si}$ (Fig. 1 and Ref. [14]) and therefore the probability of creating, by the $30 \mathrm{eV}$ radiation used in this experiment, the molecules with the internal energy corresponding to the $16.29 \mathrm{eV}$ threshold is very low. In contrast, at photon energies just above $16.29 \mathrm{eV}$, resonant processes in photoabsorption could enhance the photoemission of near-zeroenergy electrons and the production of high internal energy ions significantly. Thus, in PIY measurements the energy-determined appearance threshold is observed, whereas in the PEPICO experiment, the nonavailability of suitable vibronic levels postpones the appearance of the $\mathrm{H}_{2} \mathrm{CCl}^{+}$ions.

As seen from Table 2, the excess energy at which the first fragment ion appears is nearly equal for both molecules, indicating that the $M e-S i$ bond dissociation energy is little affected by the degree of chlorination of the rest of the molecule. In contrast, the excess energy at which the next fragment produced by chlorine loss appears is slightly different: $1.3 \mathrm{eV}$ in $\mathrm{Me}_{3} \mathrm{ClSi}$ and $1.0 \mathrm{eV}$ in $\mathrm{MeCl}_{3} \mathrm{Si}$.

The creation of the methyl-loss fragments over a broad energy range makes them suitable targets for studying kinetic energy release (KER) as a function of available excess energy. Since most of the released kinetic energy goes to the undetected light methyl fragment, such a study has low accuracy. However, we attempted to follow the KER of the $\mathrm{Cl}_{3} \mathrm{Si}^{+}$fragment of $\mathrm{MeCl}_{3} S i$ by determining the broadening of the TOF peaks due to the kinetic energy. The peak width changed from 22 to 43 ns FWHM with the increasing internal (electron binding) energy, as compared to the $15 \mathrm{~ns}$ width of the parent ion peak that has no KER broadening. Using numerical Monte Carlo simulations of the ion TOF peak shapes, the KER in the dissociation reaction was estimated to increase from about 50 to $200 \mathrm{meV}$ across the range of 12 to $17.5 \mathrm{eV}$ electron binding energy. While these values are inaccurate, they nevertheless show that the KER is very small and that only a small fraction of the available excess energy is converted into the translational kinetic energy. This is one indication that the methylloss fragments are highly stable and able to contain significant internal energy without secondary fragmentation.

The main qualitative observation is that the evolution of the CIY curves of both molecules is very similar:

- The parent molecular cation is represented by a narrow peak. 
- At slightly higher binding energy the parent ion is replaced by a fragment from which a neutral methyl group has been ejected. This fragment is then present across the whole spectrum.

- The next fragment to appear is formed by ejecting a neutral chlorine atom. In contrast to the previous fragment, its yield drops to zero (or to trace levels for $\mathrm{MeCl}_{3} \mathrm{Si}$ ) again at the highest-energy feature that corresponds to the ionization of an $a_{1}$ orbital.

- Two new, smaller fragments appear at the highest-energy feature. Their composition, however, differs for the two molecules.

The first new fragments appearing at higher energies are $\mathrm{H}_{2} \mathrm{ClSi}^{+}$in $\mathrm{Me}_{3} \mathrm{ClSi}$ and $\mathrm{ClSi}^{+}$in $\mathrm{MeCl}_{3} \mathrm{Si}$. The CIY curves of these fragments are quite similar, which suggests that they appear through the same reaction mechanism in the two molecules. One possibility is the secondary dissociation of the primary fragment from which the methyl group has been ejected:

$$
\begin{gathered}
\mathrm{Me}_{3} \mathrm{ClSi}^{+} \rightarrow \mathrm{Me}_{2} \mathrm{ClSi}^{+}+\mathrm{Me} ; \mathrm{Me}_{2} \mathrm{ClSi}^{+} \rightarrow \mathrm{H}_{2} \mathrm{ClSi}^{+}+\mathrm{C}_{2} \mathrm{H}_{4}, \\
\mathrm{MeCl}_{3} \mathrm{Si}^{+} \rightarrow \mathrm{Cl}_{3} \mathrm{Si}^{+}+\mathrm{Me} ; \mathrm{Cl}_{3} \mathrm{Si}^{+} \rightarrow \mathrm{ClSi}^{+}+\mathrm{Cl}_{2}
\end{gathered}
$$

The lack of hydrogens in the fragment from $\mathrm{MeCl}_{3} \mathrm{Si}$ is naturally explained by the above mechanism. The $\mathrm{ClSi} i^{+}$production from $\mathrm{MeCl}_{3} \mathrm{Si}$ is also plausible via the secondary dissociation of the fragment that has lost a neutral chlorine or $\mathrm{HCl}$ rather than a methyl group, by reactions suggested by Lu et al [21]:

$$
\begin{gathered}
\mathrm{MeCl}_{3} \mathrm{Si}^{+} \rightarrow \mathrm{MeCl}_{2} \mathrm{Si}^{+}+\mathrm{Cl} ; \mathrm{MeCl}_{2} \mathrm{Si}^{+} \rightarrow \mathrm{ClSi}^{+}+\mathrm{MeCl}, \\
\mathrm{MeCl}_{3} \mathrm{Si}^{+} \rightarrow \mathrm{H}_{2} \mathrm{CCl}_{2} \mathrm{Si}^{+}+\mathrm{HCl} ; \mathrm{H}_{2} \mathrm{CCl}_{2} \mathrm{Si}^{+} \rightarrow \mathrm{ClSi}^{+}+\mathrm{H}_{2} \mathrm{CCl} .
\end{gathered}
$$

However, similar reactions are not possible for the $\mathrm{H}_{2} \mathrm{ClSi}^{+}$fragment from $\mathrm{Me}_{3} \mathrm{ClSi}$.

The last fragment to appear is $\mathrm{H}_{4} \mathrm{CSi}^{+}$in $\mathrm{Me}_{3} \mathrm{ClSi}$ and $\mathrm{H}_{2} \mathrm{CCl}^{+}$in $\mathrm{MeCl}_{3} \mathrm{Si}$. It is notable that the appearance of these new fragments correlates with the disappearance of the fragment created by neutral chlorine ejection. This suggests that the chlorineloss fragment starts to undergo a second-step dissociation once there is sufficient energy available, releasing e.g. an ethyl radical:

$$
\mathrm{Me}_{3} \mathrm{ClSi}^{+} \rightarrow \mathrm{Me}_{3} \mathrm{Si}^{+}+\mathrm{Cl} ; \mathrm{Me}_{3} \mathrm{Si}^{+} \rightarrow \mathrm{H}_{4} \mathrm{CSi}^{+}+\mathrm{C}_{2} \mathrm{H}_{5}
$$

In methyltrichlorosilane a reaction producing $\mathrm{ClSi}^{+}$can also create $\mathrm{H}_{2} \mathrm{CCl}^{+}$ fragment by different charge localization:

$$
\mathrm{MeCl}_{3} \mathrm{Si}^{+} \rightarrow \mathrm{H}_{2} \mathrm{CCl}_{2} \mathrm{Si}^{+}+\mathrm{HCl} ; \mathrm{H}_{2} \mathrm{CCl}_{2} \mathrm{Si}^{+} \rightarrow \mathrm{H}_{2} \mathrm{CCl}^{+}+\mathrm{ClSi}
$$

A noticeable difference between the dissociation of the two samples is that as the excess energy increases, the $\mathrm{MeCl}_{2} \mathrm{Si}^{+}$fragment from $\mathrm{MeCl}_{3} \mathrm{Si}$ develops a weak shoulder structure (seen in Fig. 2), assigned to additional hydrogen loss producing $\mathrm{H}_{2} \mathrm{CCl}_{2} \mathrm{Si}^{+}$ions, whereas no corresponding structure $\left(\mathrm{H}_{2} \mathrm{CMe}_{2} \mathrm{Si}^{+}\right)$can be detected for the $\mathrm{Me}_{3} \mathrm{Si}^{+}$fragment from $\mathrm{Me}_{3} \mathrm{ClSi}$. 
Amongst the weaker ions that are not shown in Fig. 4 the most notable is $\mathrm{HCl}^{+}$ seen from both samples. It can be a recombination fragment, but the PEPICO map shows that its CIY does not correlate at all with the molecular orbital structure of the parent molecule. Instead, it reflects the structure of the photoelectron spectrum of the $\mathrm{HCl}$ molecule and we therefore conclude that this is an impurity ion, most likely produced through the contact of the sample with moisture in a hydrolysis reaction: $\mathrm{MeCl}_{3} \mathrm{Si}+3 \mathrm{H}_{2} \mathrm{O} \rightarrow \mathrm{MeSi}(\mathrm{OH})_{3}+3 \mathrm{HCl}$. There are also traces of the following fragments: $\mathrm{ClSi}^{+}, \mathrm{MeSi}^{+}, \mathrm{H}_{3} \mathrm{CSi}^{+}$and $\mathrm{Cl}^{+}$from $\mathrm{Me}_{3} \mathrm{ClSi}$ and $\mathrm{Cl}_{2} \mathrm{Si}^{+}, \mathrm{MeClSi}^{+}$, $\mathrm{H}_{3} \mathrm{ClSi}^{+}, \mathrm{CH}_{3}^{+}$and $\mathrm{Cl}^{+}$from $\mathrm{MeCl}_{3} \mathrm{Si}$. All of these have been observed also in PIY measurements [21].

\subsection{Electronic-state-dependency}

One can approach the electronic-state-dependency of fragmentation from two cardinally different points of view: (1) If the molecular cation is created by photoionization in an electronically excited state (by ionizing orbitals other than HOMO), then it always relaxes to the ground electronic state of the parent cation prior to the dissociation. Thus, all the internal excess energy above the ground electronic, vibrational and rotational level of the cation becomes available for dissociation and the amount of the excess energy becomes the main variable determining the dissociation patterns. (2) The relaxation to the ground ionic state is much slower than molecular dissociation and therefore the kinematics of the dissociation ought to be considered on the potential energy surface of the electronic state, in which the parent cation was initially created by photoionization. The course of the dissociation reaction is then influenced by the shape of the potential energy surface of that particular state (leading to explicit state-dependency) but also by the amount of excess energy.

Let us apply these approaches to the present results. There appears to be no direct general correlation between the MO character of the neutral molecule and the fragmentation pattern upon ionization of the corresponding orbital. This would be too naïve an approach, since the remaining $29\left(\mathrm{Me}{ }_{3} \mathrm{ClSi}\right)$ or $25\left(\mathrm{MeCl}_{3} \mathrm{Si}\right)$ valence electrons rapidly rearrange following photoionization, prior any significant nuclear movement. However, some indication of the likely fragmentation pathway is still given. The outermost MO's that correspond to the lowest binding energy structures in Fig. 1 are involved in the $\mathrm{Me}-\mathrm{Si}$ bonding but not in the $\mathrm{Cl}-\mathrm{Si}$ bonding, suggesting that the first fragmentation channel to open is the ejection of a methyl group, as indeed observed in Fig. 4.

More relevant is the electronic structure and nuclear geometry of molecular cations in different electron states. Such theoretical study has been performed for the $\mathrm{MeCl}_{3} \mathrm{Si}$ molecule and it was found that major structural changes take place when an ion is created [21]. The $M e-S i$ bond length was found to increase from about 1.84 to 2.22 $\AA$ in creation of the lowest cationic state $X\left({ }^{2} A_{1}\right)$. In the next, ${ }^{2} A_{2}$ state, the $C l-S i$ bond stretches in turn from 2.03 to $2.05 \AA$ with little change in the $M e-S i$ bond. 
These theoretical findings suggest the dynamics of the dissociation process in the form of strong vibrational Franck-Condon excitations of specific stretching modes, which with sufficient energy available leads to bond ruptures.

\section{Conclusion}

Changes in the fragmentation patterns of two methylchlorosilane molecules as a function of the internal excess energy were investigated using the electron-energy-resolved PEPICO technique. No direct correlation was found between the MO character of the neutral parent molecule and the dissociation pathways of the ionic state created by VUV-ionization of these MOs. Instead, we propose a common, simple dissociation scenario for both molecules that is consistent with the experimental findings. The degree of chlorination of the two studied methylsilane molecules does not seem to principally alter the dissociation mechanisms. The main parameter determining the dissociation pattern is the internal excess energy of the parent ion. The primary dissociation event is the ejection of either neutral chlorine atom or the methyl group. The dominance of these pathways is in good agreement with the available $a b$ initio calculations for the equilibrium geometry of lowest electronic states of the parent $\mathrm{MeCl}_{3} \mathrm{Si}^{+}$ion, that suggest the initial change of the molecular geometry that starts the dissociation process. These processes compete over a broad range of the available excess energy. At high excess energy the remaining fragment cations are created with sufficient internal energy to facilitate second-step dissociation. Notably, some of the first-step ions created by the removal of methyl group remain intact also at high internal energies across the whole studied range. It would be of interest in future experiments to extend the energy range and determine the full survival range of this fragment. In contrast, the ions created by chlorine ejection disappear at high energies and we suggest that it will always undergo second-step dissociation, once it becomes energetically possible. This information is a particular advantage of the electron-energy-resolved PEPICO technique and is not obtained by e.g. partial ion yield measurements. Further calculations of the nuclear geometries and electronic structures of the product ions are needed to confirm the proposed scenario.

\section{Acknowledgements}

Financial support from the Academy of Finland and via the EU Transnational Access to Research Infrastructures programme is acknowledged. The authors thank the Electron Spectroscopy Group of Oulu University, led by Profs. Helena and Seppo Aksela, for providing the electron spectrometer as a part of the PEPICO setup and in particular S. Urpelainen and M. Huttula for their contribution to the construction of the FinEst branchline. 


\section{References}

[1] F. Penent, P. Lablanquie, R.I. Hall, J. Palaudoux, K. Itod, Y. Hikosaka, T. Aoto, J.H.D. Eland, J. Electron Spectrosc. Relat. Phenom. 144147, 7 (2005).

[2] C. Miron and P. Morin, Nucl. Instr. and Meth. A 601, 66 (2009).

[3] HW Jochims, E Ruhl, H Baumgartel, S Tobita, S Leach, International Journal of Mass Spectrometry and Ion Processes, 167-168 35 (1997).

[4] MN Piancastelli, WC Stolte, G Öhrwall, S-W Yu, D Bull, K Lantz, AS Schlachter and DW Lindle, J. Chem. Phys. 117, 8264 (2002).

[5] LH Coutinho, MGP Homem, RL Cavasso-Filho, RRT Marinho, AF Lago, GGB de Souza and A Naves de Brito, Brazilian Journal of Physics 35, 940 (2005).

[6] E Kukk, M Huttula, J Rius i Riu, H Aksela and S Aksela, J. Phys. B 37, 2739 (2004).

[7] M Schwell, H-W Jochims, H Baumgärtel and S Leach, Chem. Phys. 353, 145 (2008).

[8] S Denifl, P Candoria, S Ptasinska P. Lim̃ ao-Vieira, V Grill, TD Märk and P Scheier, Eur. Phys. J. D 35, 391(2005).

[9] O Plekan, M Coreno, V Feyer, A Moise, R Richter, M de Simone, R Sankari and K C Prince, Phys. Scr. 78, 1 (2008).

[10] E Kukk, G Pruemper, R Sankari, M Hoshino, C Makochekanwa, M Kitajima, H Tanaka, H Yoshida, Y Tamenori, E Rachlew and K Ueda, J. Phys. B 40, 3677 (2007).

[11] E Kukk, R Sankari, M Huttula, S Mattila, E Itälä, A Sankari, H Aksela, S Aksela, Int. J. of Mass Spectrom, 279, 69 (2009).

[12] J W Keister, P Tomperi, T Baer, International Journal of Mass Spectrometry and Ion Processes, 171, 243 (1997).

[13] Y Li, T Baer, International Journal of Mass Spectrometry 218, 37 (2002).

[14] D Wang, S Li, X Wang, Y Li, B Chen and C Ding, J. Electron Spectrosc. Relat. Phenom. 82, 13 (1996).

[15] TF Block, M Biernbaum and R West, Journal of Organometallic Chemistry 131, 199 (1977).

[16] DC Frost, G Herring, A Katrib, RAN McLean, JE Drake and NPC Westwood, Canadian J of Chemistry, 49, 4033 (1971).

[17] WC Steele, LD Nichols and FGA Stone, J. Am. Chem. Soc., 84, 4441 (1962).

[18] GG Hess, FW Lampe and LH Sommer, J. Am. Chem. Soc. 87, 5327 (1965).

[19] SJ Band, IMT Davidson, CA Lambert and IL Stephenson, Chem. Commun. 723 (1967).

[20] SJ Band, IMT Davidson and CA Lambert, J. Chem. Soc. A, 2068 (1968).

[21] K T Lu, CI Ma, SY Chiang and JM Chen, J. Chem. Phys. 119, 921 (2003).

[22] KT Lu, JM Chen, JM Lee, SC Ho and HW Chang, J. Electron Spectrosc. Relat. Phenom. 144 165 (2005).

[23] DP Almeida, ACF Santos, MGP Homem, A Naves de Brito, HM Boechat-Roberty and GGB de Souza, International Journal of Mass Spectrometry 278, 32 (2008).

[24] L Szepes and T Baer, J. Am. Chem. Soc. 106, 273 (1984).

[25] M Patanen, S Urpelainen, M Huttula, R Sankari, V Kisand, E Nömmiste, E Kukk, H Aksela and S Aksela, Phys. Rev. A 80, 013414 (2009).

[26] E Kukk, R Sankari, M Huttula, A Sankari, H Aksela and S Aksela, J. Electron Spectrosc. Relat. Phenom. 155, 141 (2007).

[27] M Huttula, S Heinasmaki, H Aksela, E Kukk and S Aksela, J. Electron Spectrosc. Relat. Phenom. 156, 270 (2007).

[28] JE Reutt, LS Wang, YT Lee and DA Shirley, J. Chem. Phys. 85, 6928 (1986).

[29] MW Schmidt, KK Baldridge, JA Boatz, ST Elbert, MS Gordon, JJ Jensen, S Koseki, N Matsunaga, KA Nguyen, S Su, TL Windus, M Dupuis and JA Montgomery, J. Comput. Chem. 1347-1363, 14, (1993).

GAMESS (http://www.msg.chem.iastate.edu/gamess/)

[30] CCJ Roothaan, Rev. Mod. Phys. 69-89, 23 (1951). 
[31] MM Francl, WJ Pietro, WJ Hehre, JS Binkley, MS Gordon, DJ DeFrees and JA Pople J.Chem.Phys. 3654-3665, 77 (1982).

[32] E Kukk, Spectrum Analysis by Curve Fitting (SPANCF) - macro package for Igor Pro. Available from: http://www.geocities.com/ekukk/intro.htm 